AIAA-2002-2804

Computational Simulations of a ThreeDimensional High-Lift Wing

M. R. Khorrami

NASA Langley Research Center

Hampton, VA

M. E. Berkman, F. Li

High Technology Corporation

Hampton, VA

B. A. Singer

NASA Langley Research Center

Hampton, VA

20th AIAA Applied Aerodynamics Conference 24-26 June 2002

St. Louis, Missouri 


\title{
Computational Simulations of a Three-Dimensional High-Lift Wing
}

\author{
Mehdi R. Khorrami ${ }^{1}$ \\ NASA Langley Research Center \\ MS 128, Hampton VA \\ Mert E. Berkman ${ }^{2}$ \\ and \\ Fei $\mathrm{Li}^{3}$ \\ High Technology Corporation \\ 28 Research Drive, Hampton VA \\ Bart A. Singer ${ }^{4}$ \\ NASA Langley Research Center \\ MS 128, Hampton VA
}

\begin{abstract}
$\underline{\text { Abstract }}$
Highly resolved computational simulations of a threedimensional high-lift wing are presented. The steady Reynolds Averaged Navier-Stokes computations are geared towards understanding the flow intricacies associated with inboard and outboard flap side edges. Both moderate and high flap deflections are simulated. Computed surface pressure fields accurately capture the footprint of vortices at flap side edges and are in excellent agreement with pressure sensitive paint measurements. The computations reveal that the outboard vortex possesses higher rotational velocities and lower core pressure than the inboard vortex and therefore is susceptible to severe vortex breakdown.
\end{abstract}

\section{$\underline{\text { Introduction }}$}

Projected future growth in air travel and significant quieting of modern jet engines has brought renewed attention to the non-propulsive (airframe) component of aircraft noise. Past studies that focused on airframe noise have identified high-lift devices along with the landing gears as dominant noise producing components. ${ }^{1,2}$ Those studies have established flapside-edges as a potent noise source that deserves focused attention. The present paper continues our effort towards uncovering prominent flow structures at a flap side edge in high-lift settings. These efforts are motivated by our lack of understanding of noise

\footnotetext{
${ }^{1}$ Research Scientist, Computational Modeling and Simulation Branch, Associate Fellow AIAA.

${ }^{2}$ Research Scientist: currently with ArvinMeritor Exhaust Systems.

${ }^{3}$ Senior Scientist, Member AIAA.

${ }^{4}$ Assistant Branch Head, Computational Modeling and Simulation Branch, Senior Member AIAA.
}

producing fluid dynamical processes at a flap side edge. The deeper insight gained through this work will guide the development of simplified physics-based models that mimic flow unsteadiness (and thus noise generation mechanisms) at the edge. Ultimately, such physicsbased models will allow efficient design of quiet airplanes.

In a parallel effort to several companion experiments, our previous research focused on steady Reynolds Averaged Navier-Stokes (RANS) simulations of unswept and untapered high-lift configurations. ${ }^{3-6}$ The configurations were generic two- or three-element highlift models that consisted of a two-dimensional (2D) main element with or without a $2 \mathrm{D}$ slat and a part span flap. These early studies captured the complex nature of the flap side-edge flow field and revealed the intricacies of shear layer roll-up, multiple vortex formation, vortex merging, and vortex breakdown processes. Two important aspects of a high-lift configuration left for future exploration were the effects of sweep and taper on a flap side-edge flow field.

These aspects were addressed in a series of tests conducted at NASA Langley Research Center (LaRC) in the $14 \times 22$ foot wind tunnel during 1998-1999. The tested model is a trapezoidal (trap) wing design that provides a 3D high-lift flow environment. Extensive acoustic and limited aerodynamic measurements were obtained. Using a microphone array technique, acoustic measurements were obtained by a team from the Boeing Company. Sample ground-ward flap acoustic spectra at moderate and high flap deflections are shown in Fig. 1. At a flap deflection angle of 20 degrees, the emitted noise from the inboard and outboard side-edges are nearly similar both in 
amplitude and frequency content. At 30 degrees flap deflection, while the inboard edge shows only a moderate rise in noise levels relative to the lower flap angle, there is a marked increase $(8-10 \mathrm{~dB})$ in the amplitude of the radiated noise from the outboard edge. Clearly, the measurements point to significant differences between the established flow fields at the two side edges because of sweep and taper.

The current computational study simulates the trap wing flow field. Emphasis is placed on high resolution of the flap's side-edges. Our goals here are to capture the differences that may exist between the two flow fields as well as to highlight the prominent changes to the noise producing flow features that may occur with increasing flap deflection.

\section{Model Geometry and Computational Grid}

The trap wing is a high-lift model consisting of a constant chord leading edge slat, a main element, and a part span flap. Figure 2a displays the tested trap wing model which had a simple center body. To ease the gridding task, for our computational model the center body was removed and the wing was extended all the way to the tunnel floor. As will be shown later, this model alteration has no significant effect on local or global aerodynamic characteristics of the trap wing. Figure $2 \mathrm{~b}$ shows the trap wing geometry as simulated. Both main element and flap are swept and tapered. In the stowed position, the leading edge and trailing edge sweep are 33.89 and 16.24 degrees respectively. The simulated model has a root chord of 53.473 inches $(1.358 \mathrm{~m})$, a tip chord of 21.12 inches $(0.536 \mathrm{~m})$, a mean aerodynamic chord of 37.3 inches $(0.947 \mathrm{~m})$, and a span of 85 inches $(2.16 \mathrm{~m})$. The flap has an inboard chord of 13.56 inches $(0.344 \mathrm{~m})$, an outboard chord of 8.97 inches $(0.228 \mathrm{~m})$, and a span of 42.19 inches $(1.07 \mathrm{~m})$. The relative positions of the slat and the flap with respect to the wing (i.e., the gaps and the overlaps) were fixed to match an experimental setting of interest. The settings for the simulated configurations are presented in Table 1. The tabulated gaps and overlaps are normalized with respect to the local stowed chord. All of the trailing edges of the tested model are blunt. To ease the computational task and reduce the number of grid points required, the surfaces of respective elements were shaved smoothly (while maintaining the cambers) to produce sharp trailing edges. For a realistic comparison with the measured quantities, the entire test section of the $14 \times 22$ foot tunnel is modeled to simulate the experiment. The wind tunnel walls are treated as inviscid surfaces to avoid the additional computational cost of resolving the wall boundary layers. This assumption had previously been shown to be adequate in similar studies of high-lift configurations by Khorrami et al. ${ }^{4}$ and Berkman et al. ${ }^{5}$.

Table 1. Geometrical settings

\begin{tabular}{|l|c|}
\hline \multicolumn{1}{|c|}{ Parameters } & Setting \\
\hline Slat angle, deg & 25 \\
\hline Flap angle, deg & 20,30 \\
\hline Slat gap, \% & 1.5 \\
\hline Flap gap, \% & 1.5 \\
\hline Slat overlap, \% & 1.5 \\
\hline Flap overlap, \% & 0.5 \\
\hline
\end{tabular}

Two different configurations, corresponding to the acoustic measurements displayed in Fig.1, are computed. In both cases, the slat deflection angle is 25 degrees and the main element angle of attack is 10 degrees. The flap deflection angle is 20 degrees in one configuration and 30 degrees in the second configuration, representing aircraft approach and landing conditions, respectively.

A multi-block structured grid is used to simulate the flow past the trap wing. Limited use of patching strategy is made to reduce the total number of points. High concentrations of grid points occur adjacent to the model solid surfaces, slat cove, main element leading edge, and flap edges. The surface grid distribution is shown in Fig. 3. Near the flap side-edges, the grids are clustered in the spanwise direction to resolve edge vortices. Chordwise resolution is also high over the flap. Grid concentration in the vicinity of the outboard flap edge is displayed in Fig. 4 with a similar mesh clustering occurring at the inboard edge. The total grid is comprised of 51 blocks with nearly 17.5 million nodes. Typically, more than 20 grid points are clustered in the boundary layers adjacent to the model surface, with the first point less than $5 \times 10^{-6}$ wing-rootchords off the model surfaces.

\section{Flow Solver}

As in our previous studies, the CFL3D code $^{7}$ is used to perform the computations. CFL3D offers a wide selection of turbulence models, ranging from zero- to two-equation models. For the present effort, the oneequation Spalart-Allmaras (SA) turbulence model ${ }^{8}$ is used with a solid-body rotation modification. ${ }^{9}$ Because of the strong centrifugal force field, the cores of streamwise vortices displaying solid body rotation usually exhibit rather weak turbulent fluctuations and behave in a laminar-like manner. The present alteration dampens the turbulent viscosity in regions demonstrating solid-body-rotation and has no effects on other regions of the flow field. In previous studies (Dacles-Mariani et al. ${ }^{9}$ and Khorrami et al. ${ }^{10}$ ), the 
modified SA model was shown to produce better results for vortex dominated flows, such as the present case.

\section{$\underline{\text { Results and Discussion }}$}

Computations and postprocessing of the results are performed in a non-dimensional fashion. The scales used in our normalizations are the free stream speed of sound, density, kinematic viscosity, and the wing root chord. For the present case, reference flow variables are set to match conditions at the $14 \times 22$ test section entrance. All simulations are obtained for a free stream Mach number of 0.2 and the root chord Reynolds number of 5.65 million. Computations are done in a fully turbulent mode using the one-equation SA model with the solid-body-rotation modification.

Because of the large grid, the computations were performed on the SGI clusters of National Aerodynamic Simulation facility at NASA Ames. Each individual run utilized $52 \mathrm{CPUs}$ and slightly less than 12 GB of memory. A typical run, producing 100 iterations on the finest level, took nearly $6 \mathrm{hrs}$ of physical time or approximately $300 \mathrm{hrs}$ of CPU time. To achieve a faster and more efficient convergence rate, mesh sequencing was employed with two coarser level meshes (where successive removal of every other node provides the lower level meshes). For both 20 and 30 degree flap deflections, in a steady mode, convergence was assumed when the calculations had no changes in the lift coefficients to 3-4 significant digits with subsequent iterations. At this stage, the overall global residual displayed 5 orders of magnitude drop before leveling off. Although the residual remained flat for the 20 degree case, the residual for the higher flap angle showed a somewhat low amplitude oscillatory behavior, suggesting the onset of an unsteady event. The probable cause of residual oscillation will be discussed in the following sections. Nevertheless, the lift coefficient for the 30 degree case never displayed an oscillatory pattern and it converged to a finite value very smoothly. An estimate (in a global sense) on the grid dependency of the computed solutions is obtained via comparison of the lift coefficients. Tabulated in Table 2 are the computed lift coefficients from the midand fine-level grids. More importantly, in Table 3 we present a comparison between the fine-level computed and experimentally measured lift coefficients. Good agreement is achieved between the two sets of lift coefficient. This close agreement suggests that the removal of the center body from the simulated configuration has had minimal impact on the aerodynamic characteristics of the wing.
Table 2 Grid-resolution studies

\begin{tabular}{|c|c|c|c|}
\hline & \multicolumn{2}{|c|}{ Lift Coefficient } & \\
\hline $\begin{array}{c}\text { Flap } \\
\text { deflection }\end{array}$ & $\begin{array}{c}\text { Mid-level } \\
\text { mesh }\end{array}$ & $\begin{array}{c}\text { Fine-level } \\
\text { mesh }\end{array}$ & $\begin{array}{c}\text { Difference, } \\
\%\end{array}$ \\
\hline 20 degree & 1.10 & 1.144 & 3.8 \\
\hline 30 degree & 1.24 & 1.312 & 5.5 \\
\hline
\end{tabular}

Table 3 Computed and measured lift coefficients

\begin{tabular}{|c|c|c|c|}
\hline & \multicolumn{2}{|c|}{ Lift Coefficient } & \\
\hline $\begin{array}{c}\text { Flap } \\
\text { deflection }\end{array}$ & Computed & Measured & $\begin{array}{c}\text { Difference, } \\
\%\end{array}$ \\
\hline 20 degree & 1.144 & 1.125 & 1.69 \\
\hline 30 degree & 1.312 & 1.31 & 0.15 \\
\hline
\end{tabular}

We begin the discussion with a brief presentation of the global flow before directing our attention to the details of the flap side-edge flow fields. Figure 5 shows the pressure distribution over the entire model for the 30 degree case. Note that regions of significant pressure suction occur near the wing and flap leading edges and both flap side edges. Figure 6 illustrates a comparison of the computed chordwise pressure variation with that measured over the main wing at the 50 percent span location. Except for the two bad ports near $x=0.5$, the measured $\mathrm{Cp}$ are in remarkable agreement with the computed pressure. The small discrepancies near the trailing edge may be attributed to the sharpening of the edge in the simulation. The Mach number contours at the mid-span location for 30 degree flap deflection are presented in Fig. 7. The contour plot shows significant acceleration of the flow through the slat and flap gaps causing the Mach numbers in the vicinity of the main element and flap leading edges to approach a value nearly twice the freestream Mach number of 0.2. The recirculating zones and the corresponding low Mach numbers in the slat and main element coves are also vividly visible in Fig. 7 . The simulation for 20 degree flap shows similar global features.

As mentioned in the introduction, surface pressure distributions near flap edges were obtained using the Pressure Sensitive Paint (PSP) technique. The measured pressure distributions for the 20 degree flap deflection are shown in Fig. 8a. The middle section of the flap was not treated with PSP and therefore is assigned a value of $\mathrm{Cp}=0.0$. The flap leading edge experiences a higher suction peak towards the outboard segment. In addition, both edges display a pear-shape low-pressure region that is the footprint of the main vortex after the vortex has moved on the top surface. These region of intense low pressures are quite similar 
to the footprint of vortices for unswept and untapered flaps, reported in references. ${ }^{4-6}$ The computed pressure field on the flap is plotted in Figure 8b. The simulated field is in good agreement with PSP result and shows that the prominent flow features associated with the flap are well resolved. The corresponding $\mathrm{Cp}$ distributions for the 30 degree flap deflection are plotted in Fig. 9. Once again excellent agreement between the measured and computed pressures is shown. Much higher suction peaks at the flap leading edge and in the footprints of the edge vortices are observed. The shape and orientation of the vortex-induced suction peaks indicate that, once on top, the inboard vortex moves inward of the edge while the outboard vortex remains close to the edge. From the point of view of noise generation and scattering at sharp edges, these subtle differences have strong ramifications.

Based on the acoustic array measurements, the outboard flap edge was found to be a more potent noise source than the inboard edge thus suggesting that there may exist some fundamental differences between the two flow fields. Fortunately, the volumetric CFD database can be analyzed thoroughly to highlight these differences. The pressure contours along the inboardedge chord for 20 degree flap are plotted in Fig. 10 and the corresponding contours for the outboard edge in Fig. 11. The contour plots show the formation of a strong vortex near the bottom sharp edge and a much weaker vortex at the top sharp corner. The merging of the two vortices occurs at a station past the flap midchord when the stronger vortex has moved onto the flap top surface. The outboard vortex attains a lower pressure in its core, as it is evident from the more severe saturation of the pressure contours (hollowed regions inside the cores). Because of the centrifugal force balance, the lower the core pressure drops, the higher the vortex rotational velocities become. Similar pressure contour plots for the 30 degree flap deflection are displayed in Fig. 12 (inboard) and Fig. 13 (outboard). At the inboard edge, the vortex core attains a lower suction peak relative to the 20 degree case (Fig. 10) and maintains the low pressure beyond the flap trailing edge. At the outboard edge, initially, the vortex shows extremely low pressures in its core. However, once the vortex moves on flap top surface, within a very short distance, it experiences a severe pressure rise in its core. Typically, such rapid pressure rise is associated with the core expansion, appearance of stagnation point inside the core, and the onset of vortex breakdown.

To help understand the differences associated with the two flap settings, the spanwise lift distribution on the flap for both deflection angles is plotted in Fig. 14. Two features immediately distinguish themselves.
First, vortex lift is more prominent at the inboard edge $(\mathrm{z}=0.39)$ and its contribution is increased with increasing flap deflection. Second, vortex lift is severely diminished at the outboard edge at the high flap deflection. Given the fact that the outboard vortex experiences lower pressures in its core than the inboard vortex, the lift distribution plot reinforces our earlier assertions that, the outboard vortex path remains closer to the edge than the inboard path, and vortex breakdown first occurs at the outboard edge and at lower flap deflections.

The presence of a vortex breakdown becomes more evident when the streamwise velocity distribution in the core of vortices is viewed. A sample plot of the streamwise velocity for the 20 degree case is shown in Fig. 15. The two planes shown are slightly inward of the flap edges. Recall that the free stream velocity is $\mathrm{u}=0.2$. Due to extreme low pressures, both vortices attain a jet-like axial velocity in their cores. For the inboard vortex, the maximum velocities are typically 60-70 percent higher than the freestream velocity. The outboard vortex core show an additional 10-20 percent higher axial velocities relative to the inboard vortex. Notice that the inboard vortex maintains the jet-like behavior into regions well beyond the flap trailing edge. On the other hand, the excess velocity in the core of the outboard vortex disappears slightly downstream of the trailing edge. The corresponding axial velocity plot for the 30 degree case is displayed in Fig. 16. At the inboard edge, starting at the mid-chord region, the vortex experiences a jet-like axial velocity in its core. At this flap setting, the maximum core velocity is $70-80$ percent higher than the free stream. As the trailing edge of the flap is approached, the adverse pressure gradient causes a rapid deceleration of the vortex core velocity. Beyond the trailing edge, the vortex breaks down and there is a region of axial flow reversal. In contrast, the outboard vortex experiences the adverse pressure gradient much earlier and therefore breaks down immediately as soon as it moves on the top surface in the mid-chord region. The maximum magnitude of the reverse flow experienced by the vortices is on the order of 5-10 percent of the free stream velocity. Monitoring of the CFD database at differing iteration cycles revealed the onset of low level flow unsteadiness in the breakdown region. Given the fine spatial resolution at the side edges, it would not be surprising if the unsteady internal structure of the vortex breakdown is partially being resolved. It is believed that the observed oscillation in the global residual is related to this time-dependent activity.

The presence of vortex breakdown at a flap side edge was first reported in references $[4,5]$ and subsequently by Berkman et al. ${ }^{6}$ for unswept and untapered flaps. 
The present study indicates that vortex breakdown is not unique to those simple generic configurations and in reality occurs at any flap side edge in a high-lift setting. The detection of vortex breakdown at the outboard edge raises several important questions. Is vortex breakdown solely responsible for the increased noise levels at the flap outboard edge? Is the causality between vortex breakdown and increased noise direct or indirect? Since the internal structure of vortex breakdown oscillates at low frequencies, one may rule out the direct effect and assume that the noise sources are modified indirectly via increased Reynolds stress activities and other local flow alterations. Of course, further experiments in conjunction with accurate unsteady flow simulations are needed to address some of these important questions.

\section{Conclusions}

Steady Reynolds Averaged Navier-Stokes (RANS) simulations of a complex three-dimensional high-lift wing were conducted in an effort to understand the effect of sweep and taper on the flap-side-edge flow field. Flap deflection of 20 and 30 degrees, representing aircraft approach and landing configurations, were computed. Emphasis was placed on fine resolution of the inboard and outboard flap side edges to highlight the prominent differences between the established flow fields at the two edges. Comparison between measured and computed lift coefficients showed very good agreement. Excellent comparison between PSP measurements of flap surface pressure and simulations were obtained both qualitatively and quantitatively. Careful analysis of RANS database revealed the outboard edge vortex to be the stronger vortex, attaining lower pressures and thus higher rotational velocities in its core. Moreover, the outboard vortex path remains closer to the side edge while that of the inboard vortex is more inward of the edge. The higher suction peaks in the core of the outboard vortex make it susceptible to undergo vortex breakdown at lower flap deflections relative to the inboard vortex.

\section{Acknowledgements}

The work of the second and third authors was sponsored by NASA contract NAS1-00088 (Lockheed Martin Corporation subcontract RT46324). The computations were performed on the SGI computer clusters provided by the National Aerodynamic Simulation (NAS) Facility. The authors would like to thank Mr. Michael Wiese formerly of Computer Sciences Corporation for constructing the computational grids.

\section{$\underline{\text { References }}$}

1. Crighton, D., "Airframe Noise," Aeroacoustics of Flight Vehicles: Theory and Practice, NASA Reference Publications 1258, Vol.1, edited by $\mathrm{H}$. H. Hubbard, WRDC TR 90-3052, Aug. 1991.

2. Macaraeg, M. G., "Fundamental Investigations of Airframe Noise,” AIAA Paper 98-2224, June 1998.

3. Khorrami, M.R., Singer, B.A., and Takallu, M.A., "Analysis of Flap Side-edge Flow Field for Identification and Modeling of Possible Noise Sources," SAE paper No. 971917. Presented at the 1997 SAE Noise and Vibration Conference and Exposition, Ground Traverse, Michigan, May 1997.

4. Khorrami, M.R., Singer, B.A., and Radeztsky, R.H.J., "Reynolds Averaged Navier-Stokes Computations of Flap-Side-Edge Flowfield," AIAA J., Vol. 37, No. 1, January, pp. 14-22, 1999.

5. Radeztsky, R. H., Singer, B. A., and Khorrami, M. R., "Detailed Measurements of a Flap Side-Edge Flow Field," AIAA Paper 98-0700, Jan. 1998.

6. Berkman, M., Khorrami, M.R., Choudhari, M., and Sadowski, S., "Investigation of High-Lift Flow Field of an Energy Efficient Transport Wing," $J$. Aircraft, Vol. 37, No.1, Jan.-Feb., pp. 45-52, 2000.

7. Thomas, J., Krist, S., and Anderson, W., "NavierStokes Computations of Vortical Flows over Low Aspect-Ratio Wings," AIAA J., Vol. 28, No.2, pp. 205-212, 1990.

8. Spalart, P.R. and Allmaras, S.R., "A One-Equation Turbulence Model for Aerodynamics Flows," AIAA Paper 92-0439, 1992.

9. Dacles-Mariani, J., Rogers, S., Kwak, D., Zilliac, G., and Chow, J., "A Computational Study of Wingtip Vortex Flowfield,” AIAA Paper 93-3010, July 1993.

10. Khorrami, M. R., Li, F., and Choudhari, M., "A Novel Approach for Reducing Rotor Tip-Clearance Induced Noise in Turbofan Engines, " AIAA Paper 2001-2148 (also to appear in July 2002 issue of AIAA J.), May 2001. 


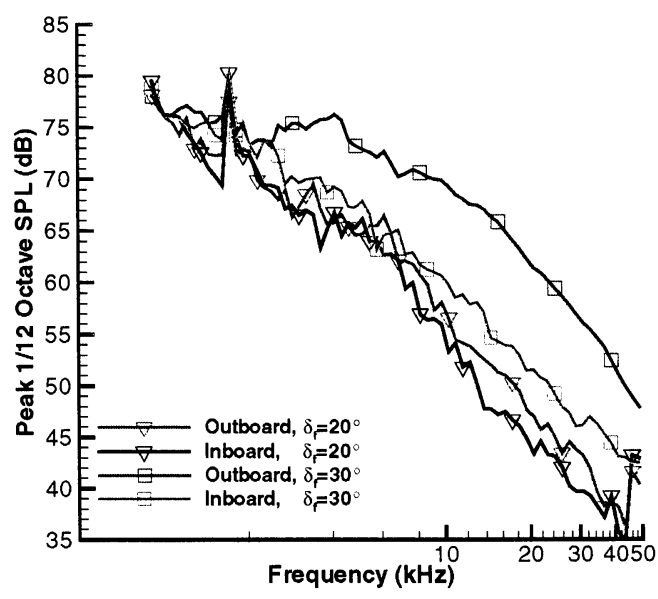

Figure 1. Effect of flap angle on radiated sound from side edges.

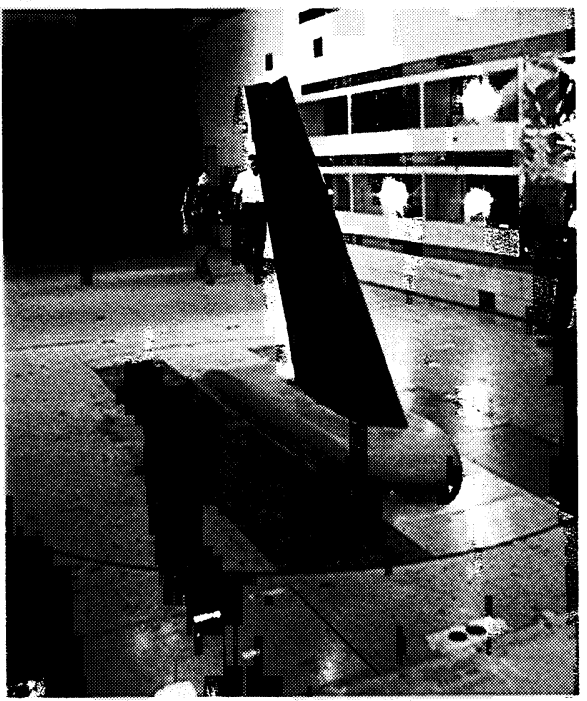

a) Tested

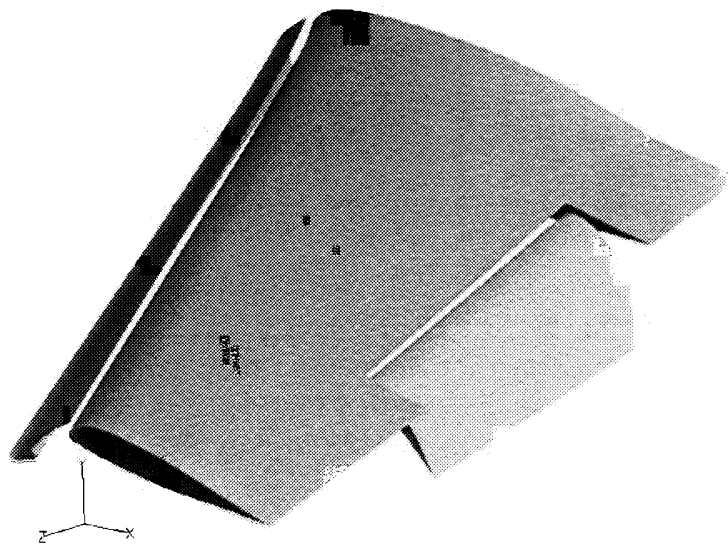

b) Simulated

Figure 2. Trapezoidal wing geometry.

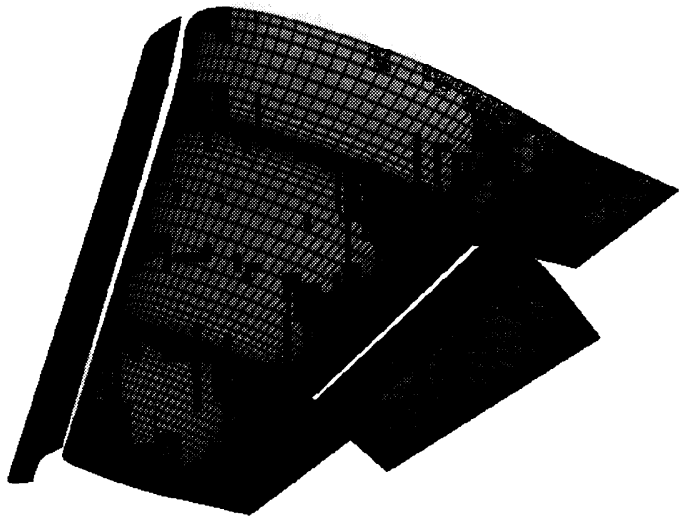

Figure 3. Surface grid distribution.

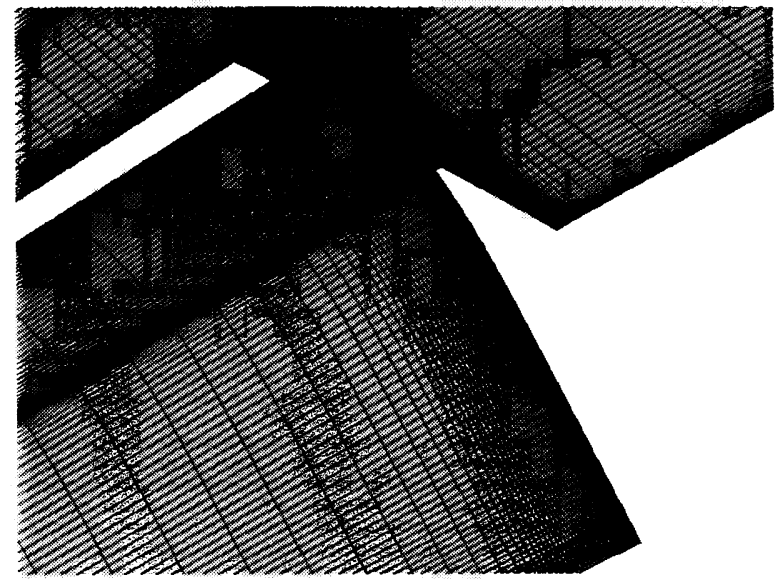

Figure 4. Grid distribution in vicinity of flap inboard edge.

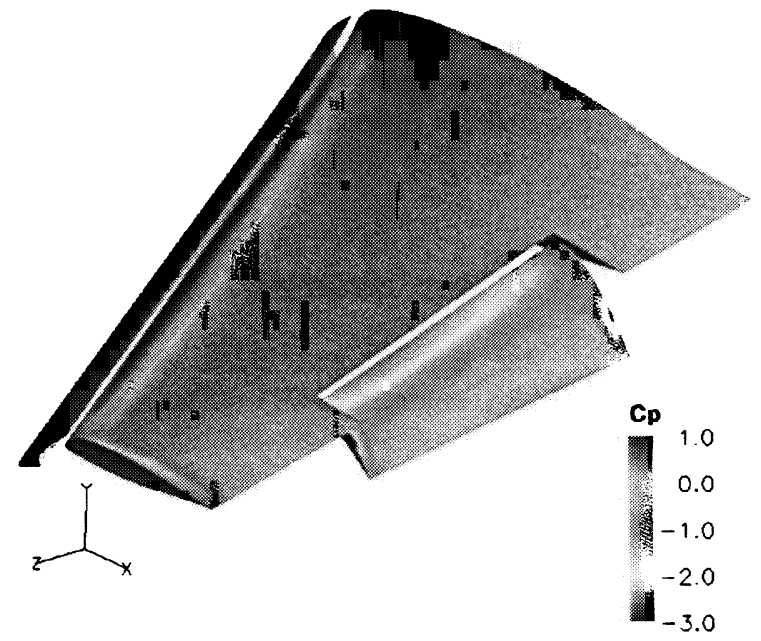

Figure 5. Computed surface pressure distribution for 30 degree flap. 

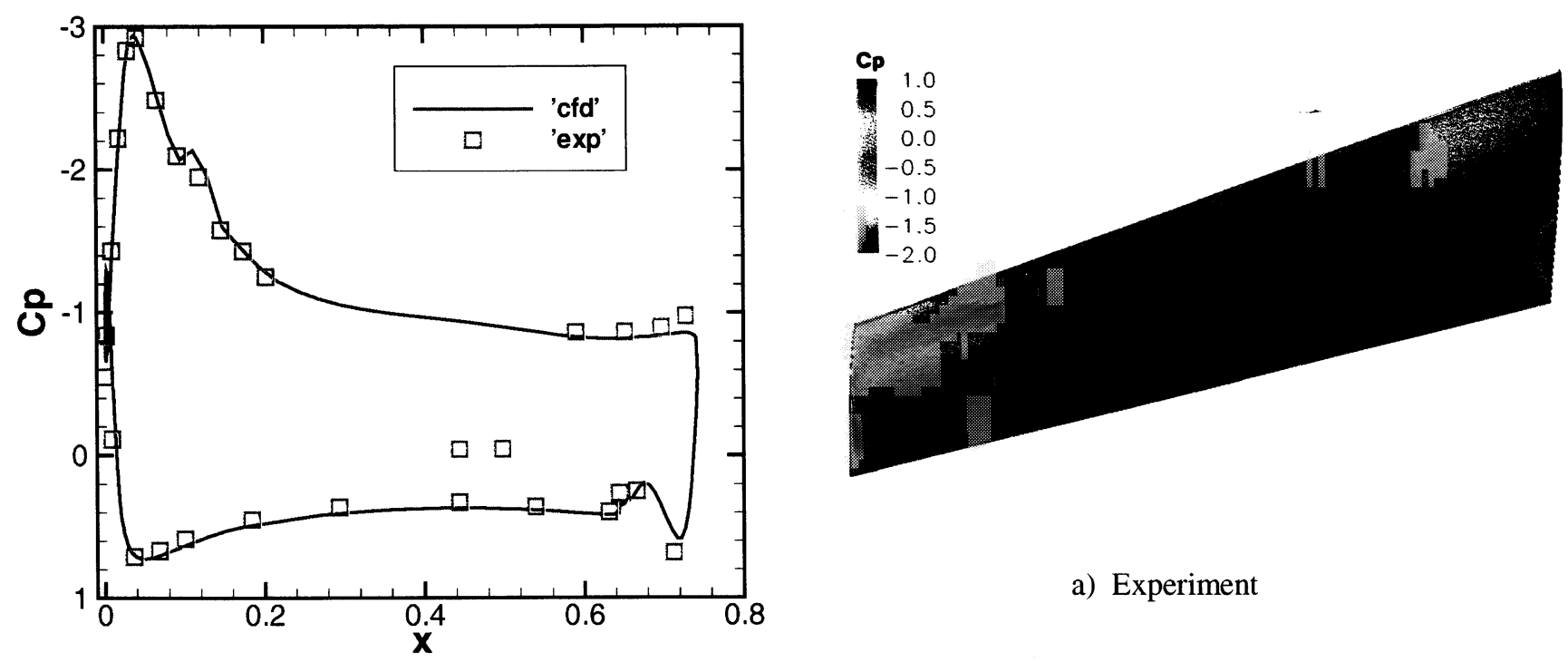

Figure 6. Chordwise pressure distribution on main element at 50 percent span.
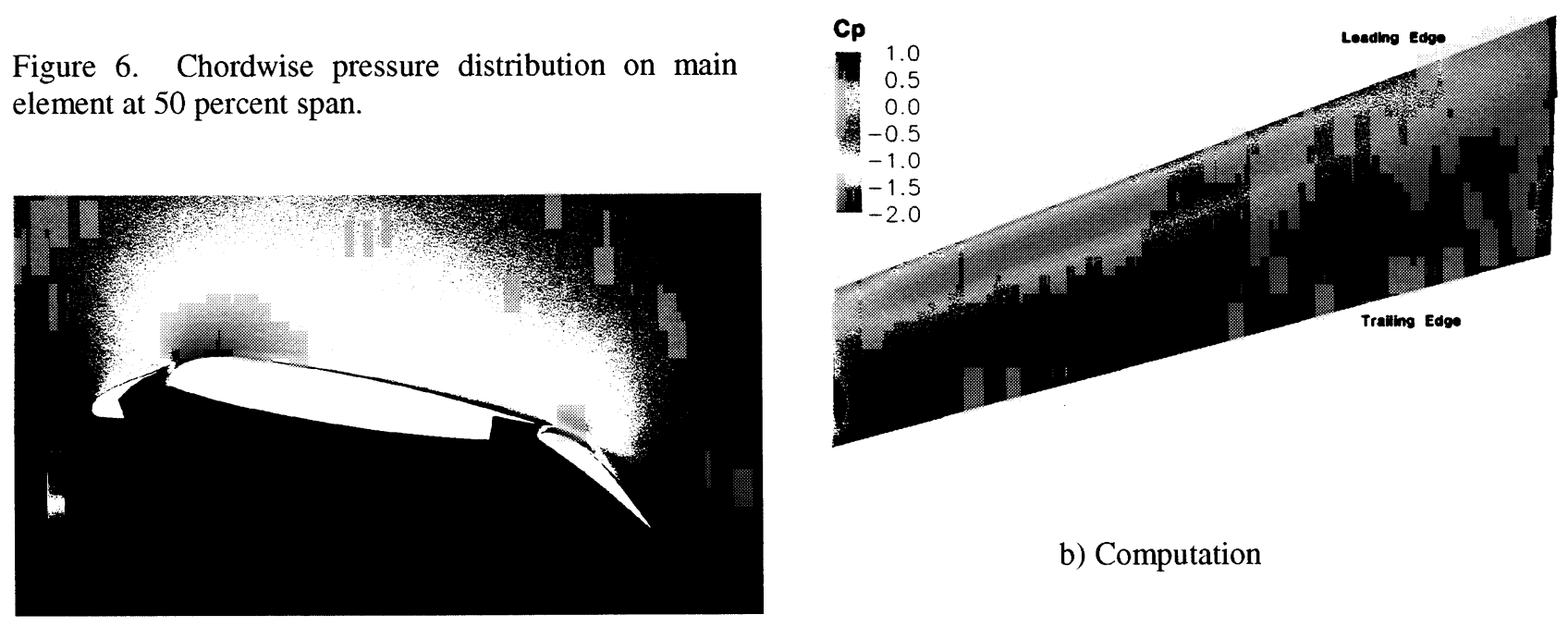

b) Computation

Figure 7. Mach contours at mid-span location for 30 degree flap.

Figure 8. Comparison between PSP and computed surface pressure on flap suction surface for 20 degree deflection. Inboard edge is on right and outboard edge on left and flow direction is from top to bottom. 


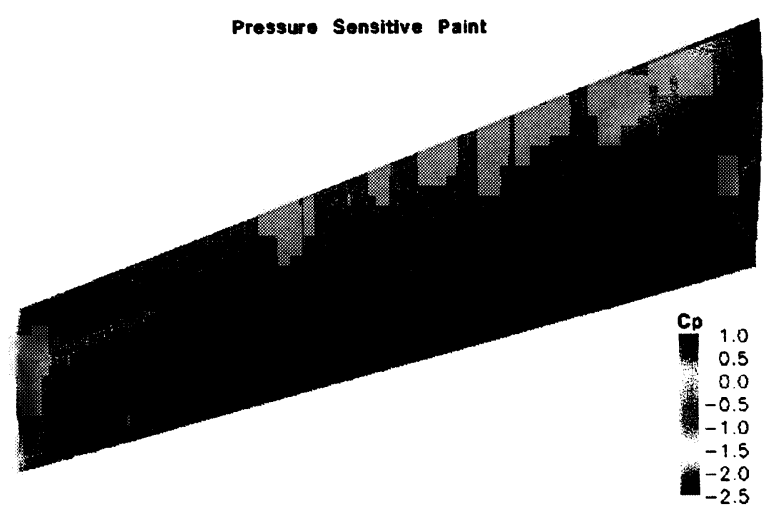

a) Experiment

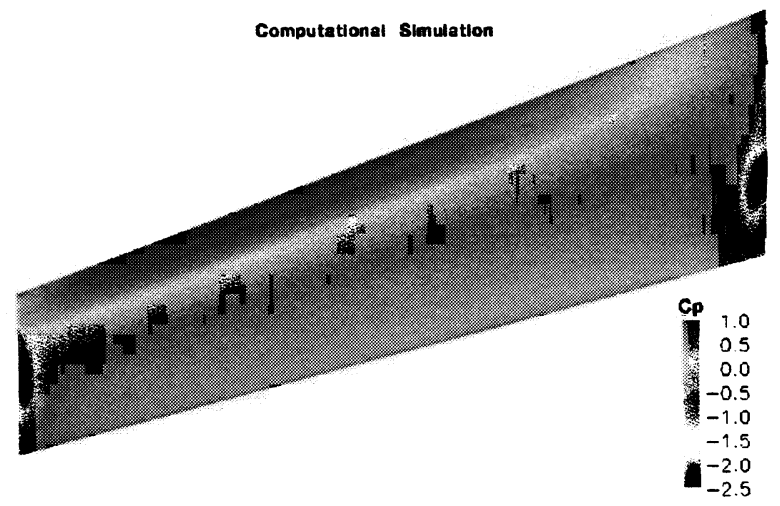

b) Computation

Figure 9. Comparison between PSP and computed surface pressure on flap suction surface for 30 degree deflection. Inboard edge is on right and outboard edge on left and flow direction is from top to bottom.

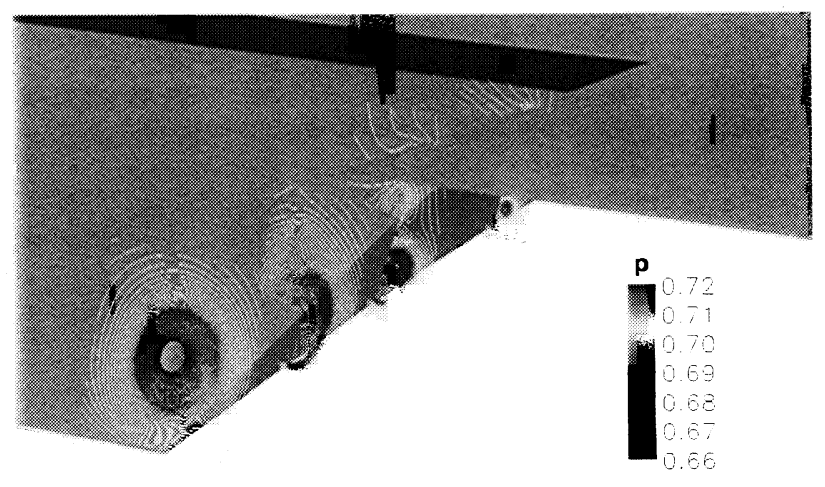

Figure 10. Pressure contours along inboard edge for 20 degree flap deflection.

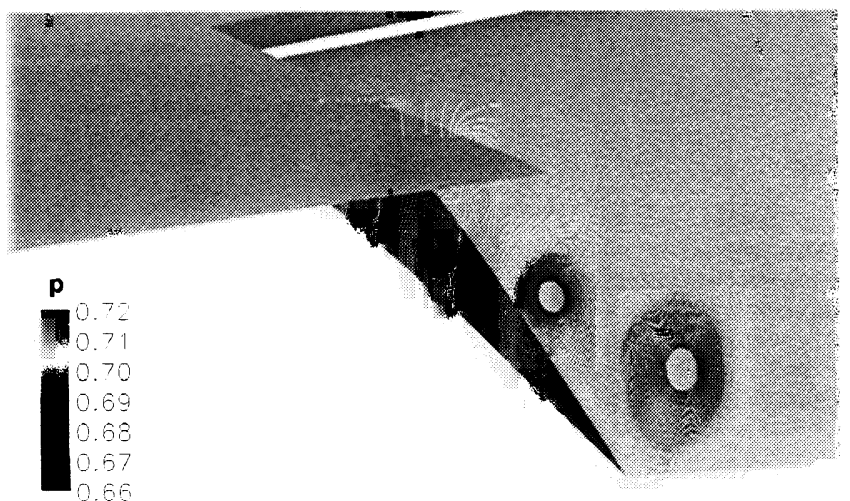

Figure 11. Pressure contours along outboard edge for 20 degree flap deflection.

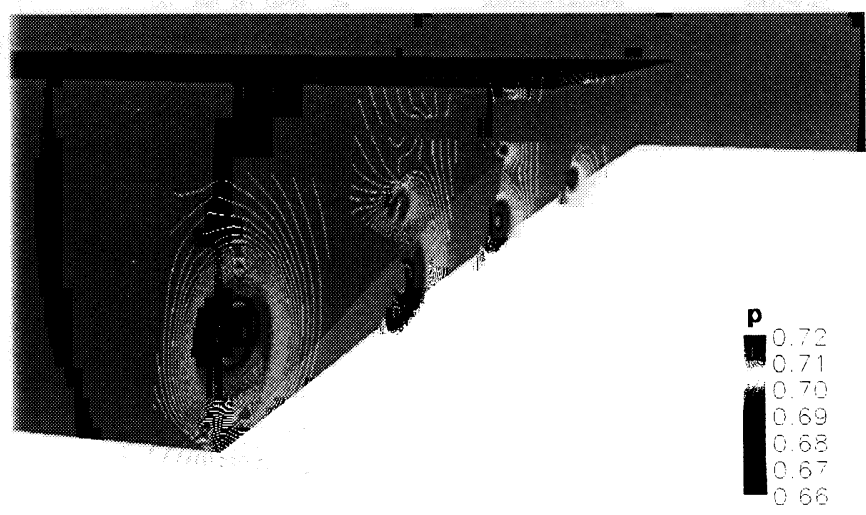

Figure 12. Pressure contours along inboard edge for 30 degree flap deflection.

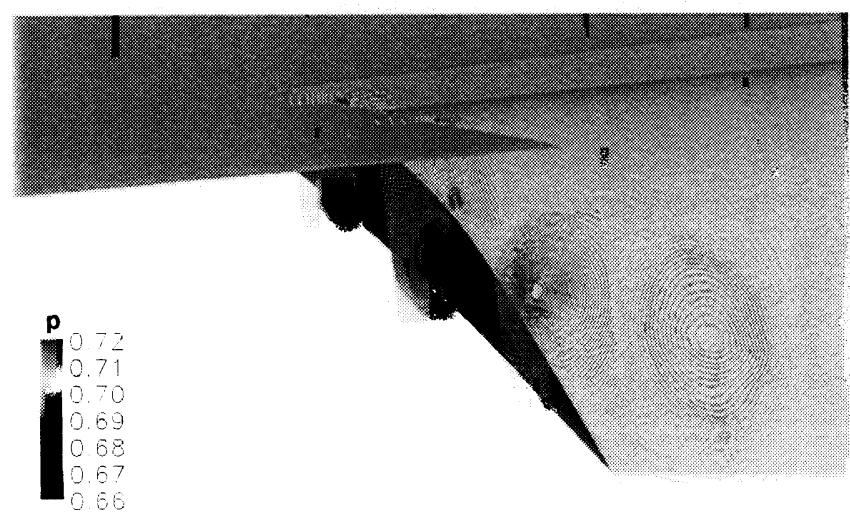

Figure 13. Pressure contours along outboard edge for 30 degree flap deflection. 


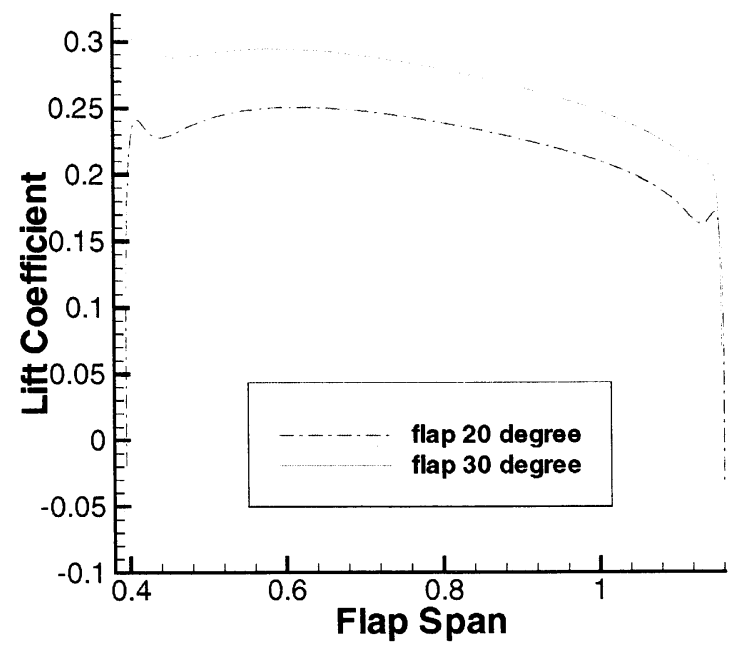

Figure 14. Spanwise lift distribution on flap. Inboard edge is at $\mathrm{z}=0.39$ and outboard edge at $\mathrm{z}=1.116$.

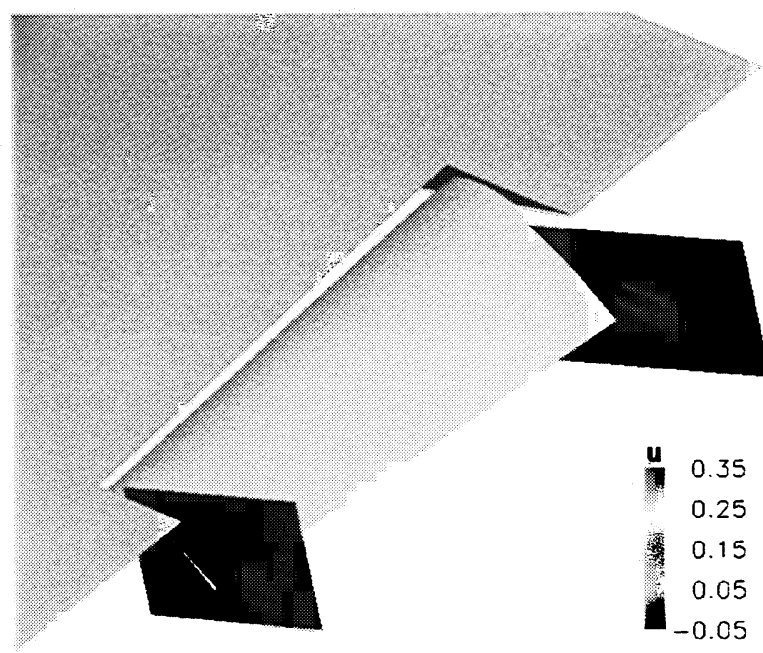

Figure 15. Streamwise velocity field in planes adjacent to side edges for 20 degree flap deflection.

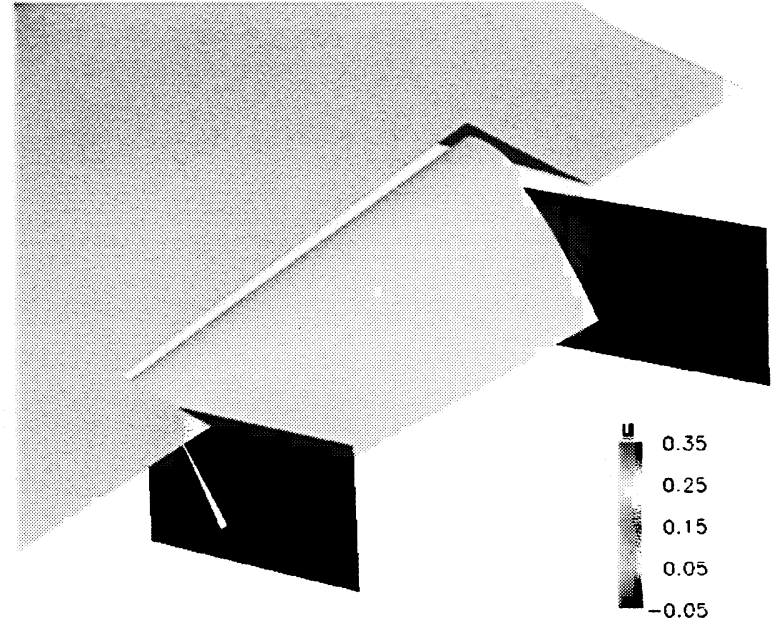

Figure 16. Streamwise velocity field in planes adjacent to side edges for 30 degree flap deflection. 